\title{
A systematic review and meta-analysis: pulmonary mycosis pathogen distribution
}

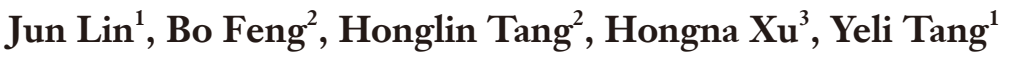 \\ ${ }^{1}$ Emergency Department, The Affiliated Urology and Nephrology Hospital of Ningbo University (Ningbo Yinzhou No. 2 Hospital), Ningbo, China; \\ ${ }^{2}$ Intensive Care Unit, ICU, The Affiliated Urology and Nephrology Hospital of Ningbo University (Ningbo Yinzhou No. 2 Hospital), Ningbo, \\ China; ${ }^{3}$ Operation Theater, The Affiliated Urology and Nephrology Hospital of Ningbo University (Ningbo Yinzhou No. 2 Hospital), Ningbo, \\ China \\ Contributions: (I) Conception and design: J Lin, Y Tang; (II) Administrative support: B Feng; (III) Provision of study materials or patients: J Lin, H \\ Tang, H Xu, Y Tang; (IV) Collection and assembly of data: All authors; (V) Data analysis and interpretation: B Feng, H Tang, H Xu; (VI) Manuscript \\ writing: All authors; (VII) Final approval of manuscript: All authors. \\ Correspondence to: Yeli Tang. Emergency Department, The Affiliated Urology and Nephrology Hospital of Ningbo University (Ningbo Yinzhou No. \\ 2 Hospital), No. 998, Qianheroad, North, Zhonghe Street, Ningbo, China. Email: tyl096030277@163.com.
}

Background: This study sought to systematically evaluate the distribution characteristics and high-risk factors of pulmonary mycosis pathogens, and provide evidence for the clinical treatment and prognosis of patients with pulmonary mycosis.

Methods: The Embase, Ovid, PubMed, Medline, and Springer databases were searched to find publications on the distribution characteristics and high-risk factors of pulmonary mycosis pathogens that had been published between the establishment of the databases and April 1, 2021. The Cochrane Handbook 5.0.2 was used to evaluate the risk of bias of the articles included in this study, and Review Manager 5.3 was used to conduct a meta-analysis of the included articles.

Results: Eleven articles were included in this study, comprising 6,415 subjects. The meta-analysis results showed that pathogen infection significantly increased the mortality of patients $[M D=2.67 ; 95 \%$ confidence interval (CI): $(1.52,4.68) ; \mathrm{Z}=3.43 ; \mathrm{P}=0.0006]$. Patient age was significantly correlated with the incidence of pulmonary mycosis $[\mathrm{MD}=1.21 ; 95 \% \mathrm{CI}$ : $(0.78,1.86) ; \mathrm{Z}=0.84 ; \mathrm{P}=0.40]$. The use of antibiotics was significantly correlated to the incidence of pulmonary mycosis $[\mathrm{MD}=1.41 ; 95 \% \mathrm{CI}:(1.15,1.72) ; \mathrm{Z}=3.30$; $\mathrm{P}=0.001]$. Glucocorticoid use was significantly correlated to the incidence of pulmonary mycosis $[\mathrm{MD}=1.81$; 95\% CI: $(1.13,2.91) ; Z=2.45 ; P=0.01]$. However, gender had no obvious correlation with the incidence of pulmonary mycosis $[\mathrm{MD}=1.21 ; 95 \% \mathrm{CI}:(0.78,1.86) ; \mathrm{Z}=0.84 ; \mathrm{P}=0.40]$. Further, no correlation was found between smoking history and the incidence of pulmonary mycosis $[\mathrm{MD}=0.86$; $95 \% \mathrm{CI}:(0.51,1.45) ; \mathrm{Z}=0.57$; $\mathrm{P}=0.57]$.

Discussion: The main types of bacterial infections in patients with pulmonary mycosis were Pseudomonas aeruginosa, Haemophilus influenzae, Streptococcus pneumoniae, Candida albicans, and Helicobacter pylori. In addition to the lungs, pathogens were found to be distributed in the intestines, urinary tract, and digestive tract. Additionally, patient age, antibiotic use, and glucocorticoid use increased the incidence of pulmonary mycosis. Thus, these factors should be paid attention to in the clinical treatment of patients with pulmonary mycosis.

Keywords: Pulmonary mycosis; distribution of pathogenic bacteria; high-risk factors; meta-analysis

Submitted May 12, 2021. Accepted for publication Jun 25, 2021.

doi: 10.21037/apm-21-1388

View this article at: https://dx.doi.org/10.21037/apm-21-1388 


\section{Introduction}

In recent years, as medical technology has continued to develop and people's living standards have continued to improve, the number of patients with immunodeficiency and the number of patients who have undergone organ transplantation, tumor radiotherapy and chemotherapy, and stem cell transplantation have also continued to increase.(1) Patients require a large number of immunosuppressive agents during clinical treatments that involve various invasive procedures, which increases the incidence and mortality of fungal infections in the hospital (2). Studies have also shown that the rate of fungal infections in hospitals in China is increasing year by year, and invasive pulmonary fungal infection (IPFI) accounts for about $50 \%$ to $60 \%$ of fungal infections in hospitals. The lung is one of the most common target organs for deep fungal infections, and the incidence of lung infections is the highest among all infections (3). Pulmonary mycosis has no specific clinical manifestations, and early diagnosis is difficult. If it is not treated in time, the mortality rate of patients can reach about $30 \%$ to $80 \%$ (4).

Pulmonary mycosis usually refers to bronchial and lung fungal inflammation or related lesions, including primary and secondary infections (5). The pathogens that causes of pulmonary mycosis are classified into pathogenic fungi and conditional pathogenic fungi according to their virulence. The death of pathogenic fungi is the main cause of primary fungal infection, and the pathogenic bacteria include histoplasma (6). Conditional pathogenic fungi are the main cause of secondary fungal infections. The pathogens of secondary fungal infections include Candida, Aspergillus, Mucor, Cryptococcus, and Penicillium marneffei, which don't have strong pathogenic to the host, but it can easily lead to deep fungal infection when a patient's immune function is weakened or destroyed (7). Due to the lack of clinical manifestation specificity, pulmonary mycosis is often difficult to distinguish from other lung diseases. Patients usually present with fever, cough, hemoptysis, chest tightness, and difficulty breathing. The imaging of fungi is not specific; however, the halo sign and air crescent sign have certain guiding significance in the diagnosis of pulmonary mycosis $(8,9)$.

Fungi can destroy host tissue cells and multiply rapidly in bronchial cavities and lung cavities, causing damage to human tissues. Their antibody antigens or metabolites may cause allergic reactions in the human body and increase the incidence of pulmonary mycosis (10). In addition, clinical studies have shown that endomycin-like active substances contained in fungal cell walls can also destroy tissue cells and cause pulmonary mycosis in patients (11).

In normal circumstances, a diagnosis of pulmonary mycosis should be considered if patients take long-term broad-spectrum antibiotics, have a history of fungal infection or acquired immunodeficiency syndrome (AIDS), use hormones for more than 3 weeks, have a long-term stay in the intensive care unit (ICU) while receiving mechanical ventilation, or have neutrophils $<0.5 \times 10^{9} / \mathrm{L}$ (12). The pathogenesis of pulmonary mycosis is complicated, and many key pathogenesis and clinical risk factors have not yet been fully clarified. A number of studies have been conducted on the related risk factors of pulmonary mycosis; however, the small sample sizes of these singlecenter studies affect the reliability of their outcomes, and controversies between some studies remain. This study sought to systematically analyze the distribution of the pathogenic bacteria of pulmonary mycosis and highrisk infection factors, and discuss the correlation between pulmonary mycosis and fungal infection. Our results revealed the law of infection and provide a reference for the clinical and nursing care of pulmonary mycosis.

We present the following article in accordance with the PRISMA reporting checklist (available at https://dx.doi. org/10.21037/apm-21-1388).

\section{Methods}

\section{Literature search strategy}

The Embase, Ovid, PubMed, Medline, and Springer databases were searched to retrieve articles that had been published between the establishment of these databases and April 1, 2021 on the distribution characteristics and highrisk factors of pulmonary mycosis pathogens. The search language was English, and the search method adopted a combination of subject words and free words. English search terms included "pulmonary mycosis," "pulmonary fungal disease," "fungal infection," "invasive pulmonary fungal infection," "lung," "respiratory," "pathogenic bacteria," "high risk factors," and "IPFI." Next, "and" or "or" joint searches were conducted using the search terms. The literature search was carried out by two researchers independently.

\section{Inclusion and exclusion criteria for articles}

Articles were included in the meta-analysis if they met the 
following inclusion criteria: (I) the subjects of the study were patients with pulmonary mycosis, regardless of gender and age; (II) the study type was a case control, the definition of risk factors was similar, and the language was English; (III) the experimental group was a fungal infection group and the control group was a fungal non-infection group; and (IV) the research indicators included patient mortality, the site of infection, the type of infection, and high-risk factors.

Articles were excluded from the meta-analysis if they met any of the following exclusion criteria: (I) the research objects were non-pulmonary mycosis patients, animals, or cells; (II) the articles were unpublished (e.g., theses) or in a language other than English; (III) the articles were republished; and/or (IV) the articles contained incomplete research data, making it impossible to calculate the corresponding indexes.

\section{Literature screening}

To screen the literature, two evaluators independently screened the articles. After the literature search, the bibliographies of the articles were imported into the Note Express 3.2 literature manager to establish a literature database. Note Express 3.2 was then used to check and eliminate duplicate articles. After the initial screening, two assessors continued to manually screen the articles. First, the titles and abstracts of the retrieved articles were read, and articles that obviously did not meet the inclusion criteria were excluded. Next, the full text of each article was read carefully to determine whether it met the inclusion or exclusion criteria. If the two evaluators disagreed, they discussed the article and reached a decision together. If a consensus could not be reached, a third-party arbitration decision was made.

\section{Data extraction}

The two researchers independently extracted the data in the literature and used Excel spreadsheets to organize the data. The information extracted from the literature included basic information about the article (i.e., the title of the article, the year of publication, the source of the article, the first author, and author information), general patient information (i.e., gender, age, sample size, length of illness, and baseline comparability), research plan design, intervention measures and control measures, testing indicators, and outcome data. After the data extraction, the two researchers conducted a cross-check. If the data extracted by the two researchers were inconsistent, the inconsistency was discussed and resolved. If a consensus could not be reached, a third-party arbitration decision was made.

\section{Quality assessment}

The bias-risk assessment criteria specified in the Cocbrane Handbook for Systematic Reviews of Intervention 5.0.2 were adopted to evaluate the risk of bias of the included articles. The evaluation content included: (I) whether it was a random sequence (i.e., whether a random number table or other random method had been used to randomly group the research objects); (II) whether allocation hiding was implemented (i.e., whether random grouping was implemented and the subjects remained confidential); (III) whether the subjects were blinded (i.e., whether the subjects of the clinical research study were aware they were participating in the research and whether they knew that they were in the experimental group or the control group); (IV) whether the outcome assessor was blinded (i.e., whether the researcher or outcome assessor knew the group of the subject); (V) data integrity (i.e., whether the research data was complete and whether there was any missing data); (VI) selective report (i.e., whether there was a selective report); and (VII) whether there were other biases. If the data extracted by the two researchers were inconsistent, the inconsistency was discussed and resolved. If a consensus could not be reached, a third-party arbitration decision was made.

\section{Statistical analysis}

The Cocbrane Handbook for Systematic Reviews of Interventions 5.0.2 was used to evaluate the risk of literature bias. STATA 11.0 was employed to merge the statistics of the included article. Review Manager 5.3 was employed for the meta-analysis of the combined statistics and to draw forest and funnel plots. The indexes in this study were all binary variables. Relative risk was the effect size, and the $95 \%$ confidence interval (CI) was calculated. When it was found that the research results of various articles could be combined, a meta-analysis was conducted. The $\mathrm{I}^{2}$ test was used to evaluate the heterogeneity of the included articles. The greater the $\mathrm{I}^{2}$, the greater the heterogeneity. If the $\mathrm{I}^{2}$ was $>50 \%(\mathrm{P}<0.05)$, and if the source of the heterogeneity could not be explained, a random-effects model (REM) (with a combined effect size) was used for the metaanalysis. If $\mathrm{I}^{2}$ was $<50 \%(\mathrm{P}>0.05)$, which represented good 


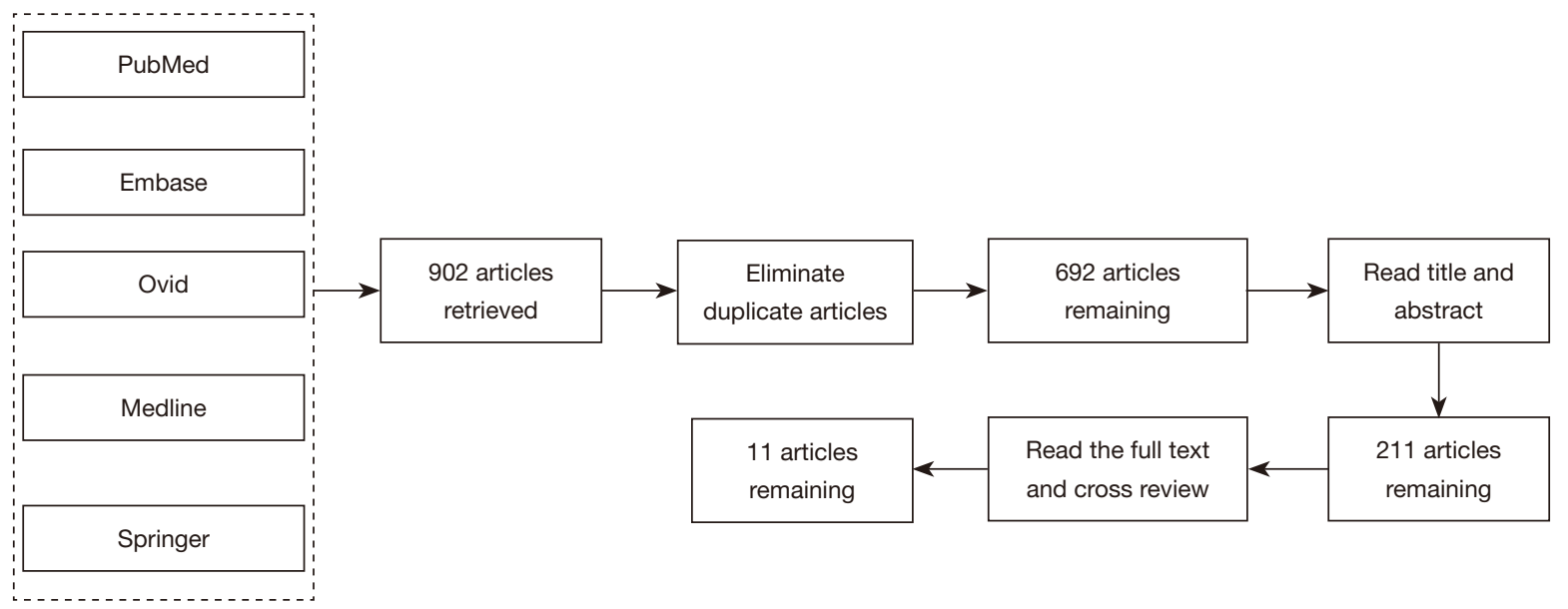

Figure 1 Literature retrieval process.

heterogeneity in the articles, a fixed-effects model (FEM) (with a combined effect size) was used for the meta-analysis. The combined effect-size test adopted a u test and $95 \%$ CI. The $\mathrm{u}$ test result was expressed as a $\mathrm{P}$ value, and a $\mathrm{P}<0.05$ indicated that the difference was statistically significant. Binary variables were tested with $95 \%$ CIs. When the $95 \%$ CI was $>1$ or $<1$, the difference was statistically significant. When the $95 \%$ CI contained 1, the difference was not statistically significant. Continuous variables were tested using $95 \%$ tests. When the $95 \%$ CI was $>0$ or $<0$, the difference was statistically significant.

\section{Results}

\section{Literature search results}

Five English databases were used to conduct a preliminary search of the data using the corresponding keywords. A total of 902 related articles were retrieved. Among them, 269 related articles were retrieved from PubMed, 166 from Embase, 201 from Medline, 164 from Springer, and 102 from Ovid. After the preliminary search, Endnote X8 was employed to eliminate duplicate articles, and 692 articles remained. Next, two literature reviewers read the titles and abstracts of the articles, and excluded 481 articles that obviously did not meet the inclusion criteria. The remaining 211 articles were carefully read and cross-checked by the two reviewers, and any article that did not meet the inclusion and exclusion criteria was eliminated. Ultimately, a total of 11 articles (13-23) were included in this study. The 11 articles contained a total of 6,415 research subjects, including 1,529 patients in the infected group and 4,886 patients in the uninfected group (see Figure 1 and Table 1).

\section{Bias-risk assessment of included articles}

The Cochrane Handbook (version 5.0.2) of the systematic review writing manual was used to evaluate the risk of bias in the 11 articles included in this study. Review Manager 5.3 was employed to output the risk of bias chart (see Figures 2,3). The risk of bias in this study included: (I) whether it was a random sequence [randomness was mentioned in the study of Shah et al., implied as low risk, and randomness was not reported in the study of Hashemi et al., implied as unclear risk. Prina et al. clearly mentioned in their study that the grouping method was "non-random", indicating high risk]; (II) whether there was assigning concealment [allocation concealment was mentioned in the study of Shah et al., suggested as low risk, and allocation concealment was not mentioned in the study of Hashemi et al., suggested as unclear risk]; (III) whether the subjects were blinded [blind subjects were mentioned in the study of $\mathrm{Li}$, indicating low risk, and blind subjects were not mentioned in the study of Shah et al, indicating unclear risk]; (IV) whether the outcome evaluator was blinded [blind outcome evaluators were suggested in the study of Shah et al., suggested as low risk, while blind outcome evaluators were not mentioned in the study of Hashemi et al., suggested as unclear risk]; (V) data integrity [the data of 11 studies were complete, which indicated a low risk]; (VI) selective reporting [11 articles did not have selective reporting, which indicated a low risk]; and (VII) whether there was other bias [for 11 articles, no judgement could 
Table 1 Basic characteristics of articles included in this study

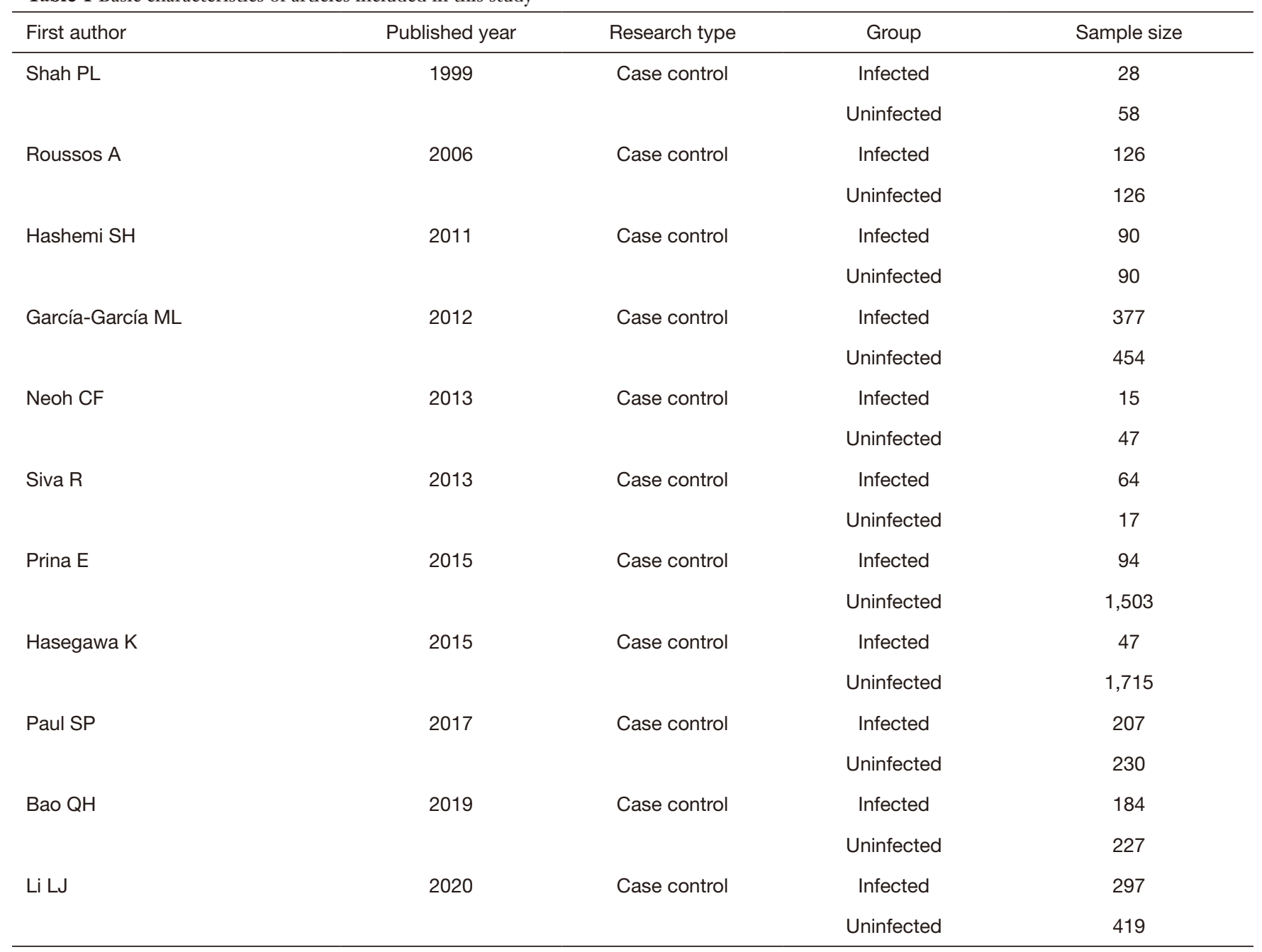

be made as to whether there were any other biases, which indicated that the risk was not clear].

\section{Type of pathogenic infections}

Eight of the 11 articles included in this study analyzed the types of pathogenic bacteria infection in patients, and a total of 4,431 subjects were included. Pseudomonas aeruginosa, Haemophilus influenzae, Streptococcus pneumoniae, and Candida albicans research heterogeneity was low $\left(\mathrm{I}^{2}<50 \%\right)$. A FEM was used for the analysis, and the Helicobacter pylori study was highly heterogeneous $\left(\mathrm{I}^{2}=68 \%\right)$. A REM was used for the meta-analysis (see Figure 4). The results showed that the combined effect of Pseudomonas aeruginosa was $\mathrm{MD}=1.86 ; 95 \% \mathrm{CI}$ : $(1.35-2.54) ; Z=3.85$
$(\mathrm{P}=0.0001)$. The combined effect of Haemophilus influenzae was $M D=1.67 ; 95 \%$ CI: $(1.18-2.36) ; Z=2.91$ $(\mathrm{P}=0.004)$. The combined effect of Streptococcus pneumoniae was $\mathrm{MD}=1.52 ; 95 \% \mathrm{CI}$ : $(1.10-2.09) ; \mathrm{Z}=2.55$ $(\mathrm{P}=0.01)$. The combined effect of Helicobacter pylori was $\mathrm{MD}=2.04 ; 95 \% \mathrm{CI}$ : (1.39-2.98); $\mathrm{Z}=3.06$ ( $\mathrm{P}=0.0003)$. The combined effect value of Candida albicans was MD $=1.53 ; 95 \%$ CI: $(1.06-2.22) ; \mathrm{Z}=2.26 ;(\mathrm{P}=0.02)$. There was a statistically significant difference between the results of the five bacterial infection types in the infected group and the uninfected group, which suggested that the combined bacterial infections of patients with pulmonary mycosis were mainly Pseudomonas aeruginosa, Haemophilus influenzae, Streptococcus pneumoniae, Helicobacter pylori, and Candida albicans. Thus, these bacterial infections should be 


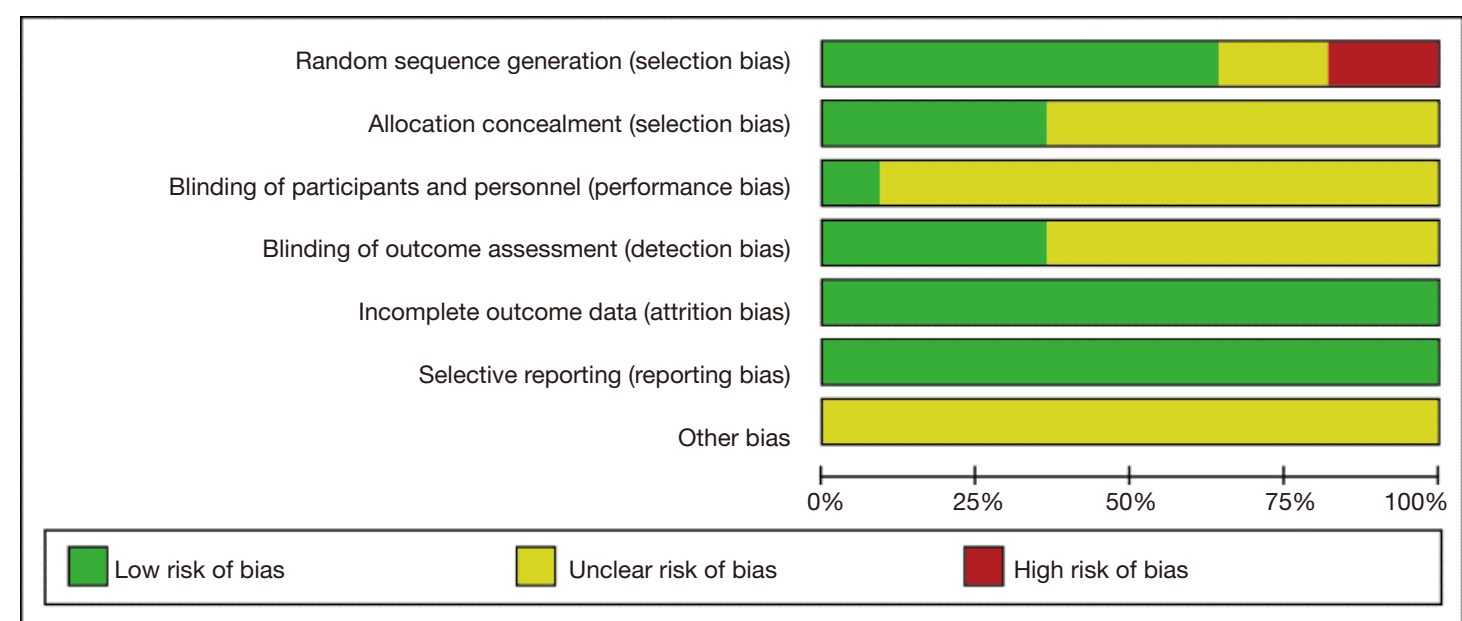

Figure 2 The bias evaluation bar graph of the included articles.

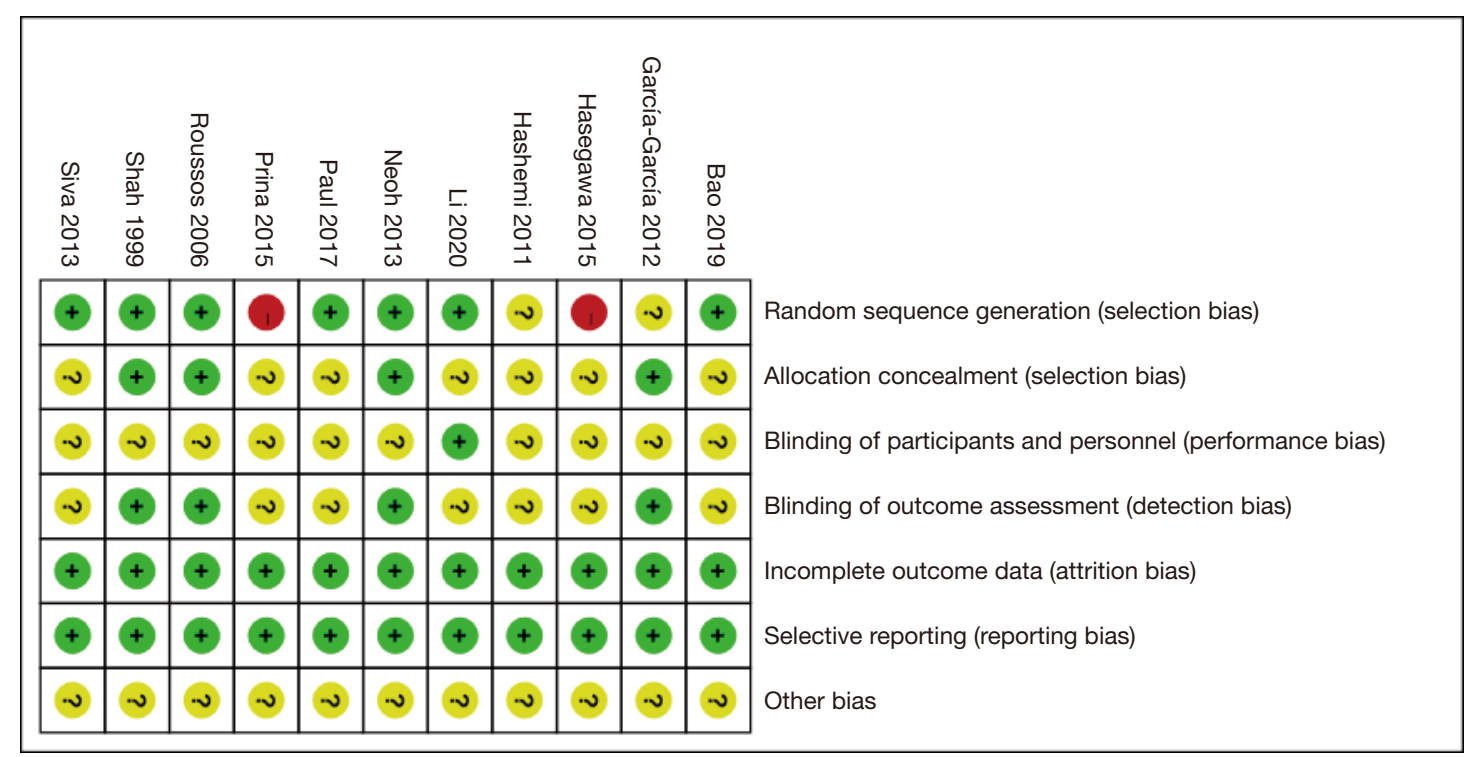

Figure 3 The bias-risk assessment diagram of the included articles.

paid attention to in the clinical treatment of patients with pulmonary mycosis.

\section{Fungal infection site characteristics}

Of the 11 articles included in this study, 6 (comprising a total of 3,894 patients) examined the infection sites of pathogenic bacteria in patients. The intestinal, urinary tract, and digestive tract infection studies had low heterogeneity $\left(\mathrm{I}^{2}<50 \%\right)$, and a FEM was used. The study of lung infection was highly heterogeneous $\left(\mathrm{I}^{2}=65 \%\right)$, and a $\mathrm{REM}$ was used for the meta-analysis (see Figure 5). The results showed that the combined result of the lung infection effect was $M D=1.55$; 95\% CI: $(1.28-1.89) ; \mathrm{Z}=4.41(\mathrm{P}<0.0001)$. The combined result of the intestinal infection effect was $\mathrm{MD}=1.37 ; 95 \%$ CI: (1.12-1.67); $\mathrm{Z}=3.06$ ( $\mathrm{P}=0.002)$. The combined result of the urinary tract infection effect was $\mathrm{MD}=1.32 ; 95 \% \mathrm{CI}$ : (1.06-1.63); $\mathrm{Z}=2.48(\mathrm{P}=0.01)$. The combined result of the digestive tract infection effect value was $\mathrm{MD}=1.70 ; 95 \% \mathrm{CI}$ : (1.18-2.44); $\mathrm{Z}=2.85$ ( $\mathrm{P}=0.004)$. The comparison results of the fungal infection sites between the infected group and the uninfected group showed statistically significant differences. 


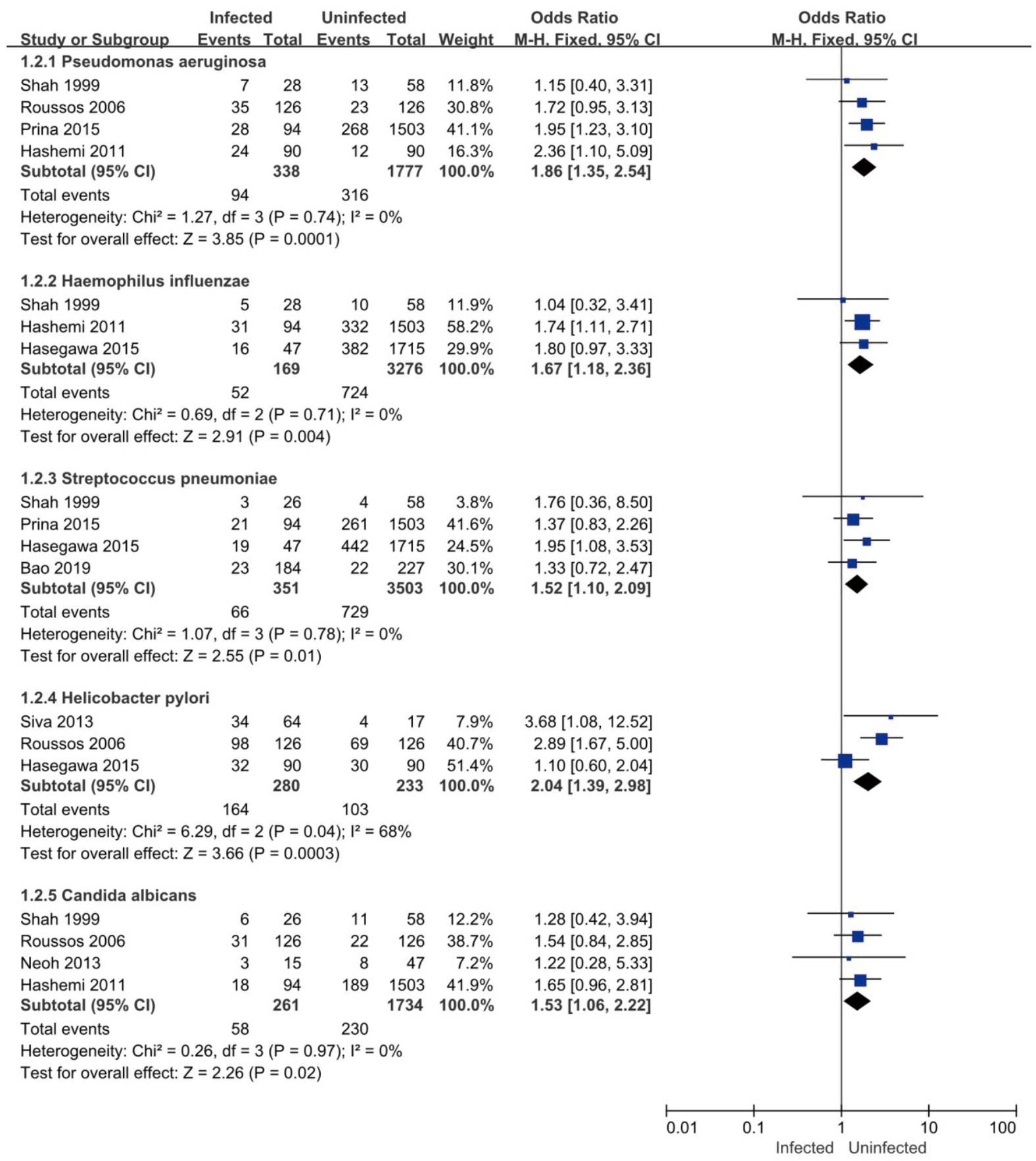

Figure 4 Forest plot of the composition ratios of fungal infections and mixed bacterial infections in patients with pulmonary mycosis.

\section{Published bias analysis of the types and distribution characteristics of pathogenic bacteria in pulmonary mycosis}

Review Manager 5.3 was employed to draw a funnel plot of the types and distribution characteristics of pulmonary mycosis pathogens and perform the publication bias analysis. The results are shown in Figure 6. Each point in the funnel chart displaying the types and distribution characteristics of pathogenic bacteria of pulmonary mycosis, representing each independent study included, basically fell within the credible interval, and showed obvious symmetry. 


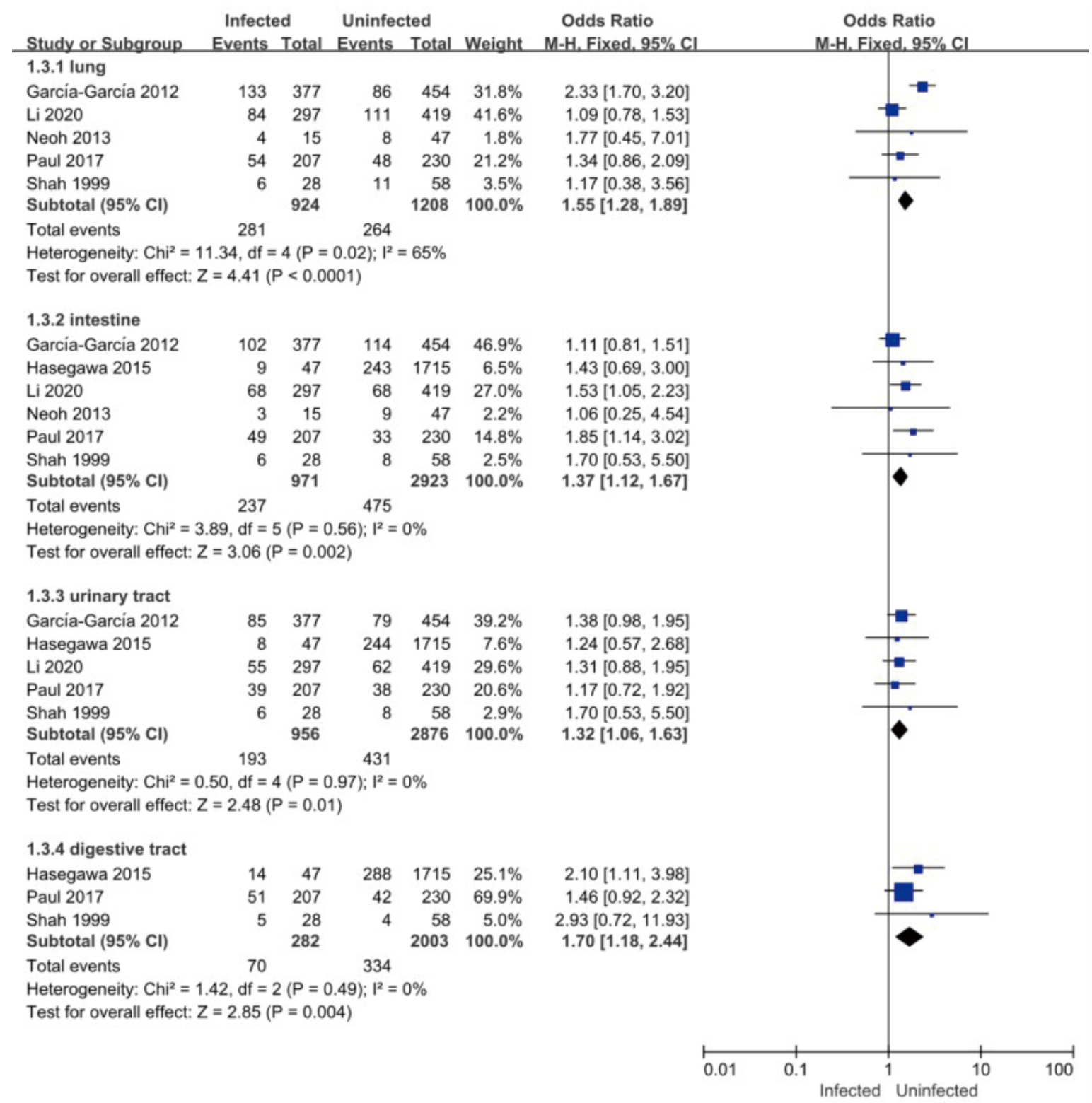

Figure 5 Forest plot of the distribution characteristics of fungal infections in patients with pulmonary mycosis.

Thus, the publication bias on the types and distribution characteristics of pulmonary mycosis pathogens appeared to be low.

\section{Patient mortality analysis}

Four of the 11 articles included in this study reported on the mortality of patients in the infected and uninfected groups. A total of 734 subjects were included in the analysis, including 353 patients in the infected group (with 46 deaths and a mortality rate of $13.03 \%$ ), and 381 patients in the uninfected group (with 20 deaths and a mortality rate of $5.25 \%$ ). The results of the heterogeneity test showed that the included 4 studies had good homogeneity $\left(\mathrm{I}^{2}=0 \%\right.$; $\mathrm{P}=0.67)$. Thus, a FEM was used for the analysis. The analysis results are shown in Figure 7. The combined effect of the meta-analysis was $\mathrm{MD}=2.67$; $95 \% \mathrm{CI}$ : $(1.52,4.68)$; $\mathrm{Z}=3.43(\mathrm{P}=0.0006)$. The difference in mortality between the infected group and the uninfected group was statistically significant, indicating that pathogen infection can increase 
A

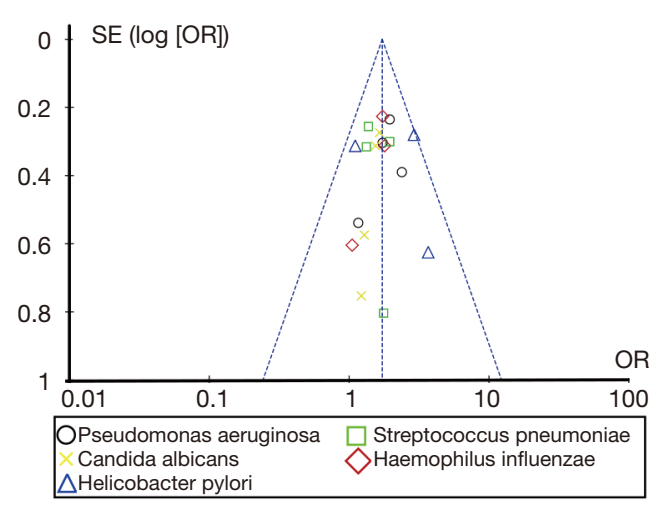

B

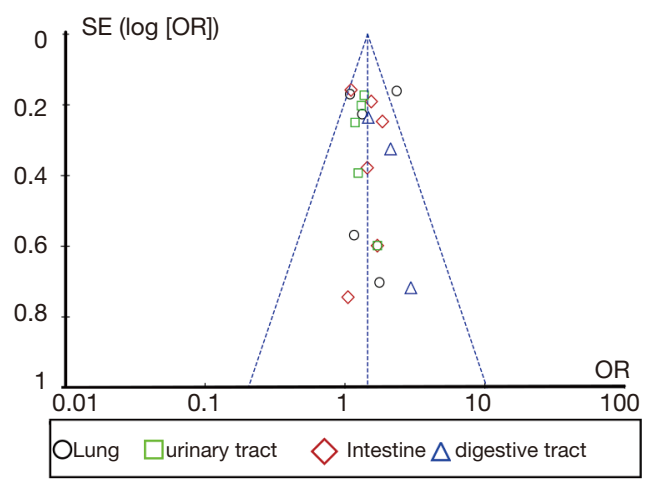

Figure 6 Analysis of publication bias of pathogen types and distribution characteristics of pulmonary mycosis. (A) Distribution types of pathogens; (B) distribution characteristics of pathogens.

\begin{tabular}{|c|c|c|c|c|c|c|c|c|c|c|}
\hline Study or Subgroup & $\begin{array}{l}\text { Infecte } \\
\text { Events }\end{array}$ & $\begin{array}{l}\text { T } \\
\text { Total }\end{array}$ & $\begin{array}{l}\text { Uninfec } \\
\text { Events }\end{array}$ & $\begin{array}{l}\text { cted } \\
\text { Total }\end{array}$ & Weight & $\begin{array}{l}\text { Odds Ratio } \\
\text { M-H. Fixed. } 95 \% \mathrm{Cl}\end{array}$ & & $\begin{array}{r}\text { Odds } \\
\text { M-H. Fixe }\end{array}$ & $\begin{array}{l}\text { Ratio } \\
\text { d. } 95 \% \mathrm{Cl}\end{array}$ & \\
\hline Bao 2019 & 22 & 184 & 11 & 227 & $54.1 \%$ & $2.67[1.26,5.66]$ & & & & \\
\hline Hashemi 2011 & 13 & 90 & 4 & 90 & $21.4 \%$ & $3.63[1.14,11.60]$ & & & & \\
\hline Neoh 2013 & 3 & 15 & 3 & 47 & $7.2 \%$ & $3.67[0.65,20.54]$ & & & & \\
\hline Siva 2013 & 8 & 64 & 2 & 17 & $17.3 \%$ & $1.07[0.21,5.58]$ & & & & \\
\hline Total $(95 \% \mathrm{Cl})$ & & 353 & & 381 & $100.0 \%$ & $2.67[1.52,4.68]$ & & & & \\
\hline Total events & 46 & & 20 & & & & & & & \\
\hline \multicolumn{7}{|c|}{$\begin{array}{l}\text { Heterogeneity: } \mathrm{Chi}^{2}=1.57, \mathrm{df}=3(P=0.67) ; \mathrm{I}^{2}=0 \% \\
\text { Test for overall effect: } Z=3.43(P=0.0006)\end{array}$} & 0.001 & $\begin{array}{l}0.1 \\
\text { Infected }\end{array}$ & 10 & 1000 \\
\hline
\end{tabular}

Figure 7 Forest plot of the relationship between pathogen infection and death.

the mortality of patients with pulmonary mycosis.

\section{Relationship between pathogenic bacteria infection and gender}

Among the 11 articles included in this study, 7 reported on the gender of patients in the infected and uninfected groups. A total of 3,419 patients were included in the study, including 914 patients in the infected group (of whom 633 or $69.26 \%$ were men). There were 2,505 patients in the uninfected group (of whom 1,644 or $65.63 \%$ were men). The results of the heterogeneity test showed that the included 7 studies were quite heterogeneous $\left(\mathrm{I}^{2}=76 \%\right.$; $\mathrm{P}=0.0003)$. Thus, a REM was used for the analysis. The analysis results are shown in Figure 8. The combined effect size of the meta-analysis was $\mathrm{MD}=1.21 ; 95 \% \mathrm{CI}$ : $(0.78$, 1.86); $\mathrm{Z}=0.84(\mathrm{P}=0.40)$. There was no significant difference between the gender of the infected group (male) and the uninfected group (male), which indicated that gender did not increase the risk of pulmonary mycosis.

\section{Relationship between pathogenic bacteria infection and age}

Five of the 11 articles included in this study reported on the gender of patients in the infected and uninfected groups. A total of 2,687 subjects were enrolled, including 590 patients in the infected group (of whom 299 patients were aged over 60 years), and 2,097 patients in the uninfected group (of whom 808 patients were aged over 60 years). The heterogeneity test results showed that the heterogeneity among the included 5 studies was small $\left(\mathrm{I}^{2}=19 \% ; \mathrm{P}=0.29\right)$. Thus, a FEM was used for the analysis. The analysis results are shown in Figure 9. The combined effect of the metaanalysis was $\mathrm{MD}=1.51 ; 95 \% \mathrm{CI}:(1.23,1.86) ; \mathrm{Z}=3.88$ $(\mathrm{P}=0.0001)$. There was a significant statistical difference between the infected and uninfected groups among patients aged over 60 years. Thus, being aged over 60 years can increase the risk of pulmonary mycosis. 


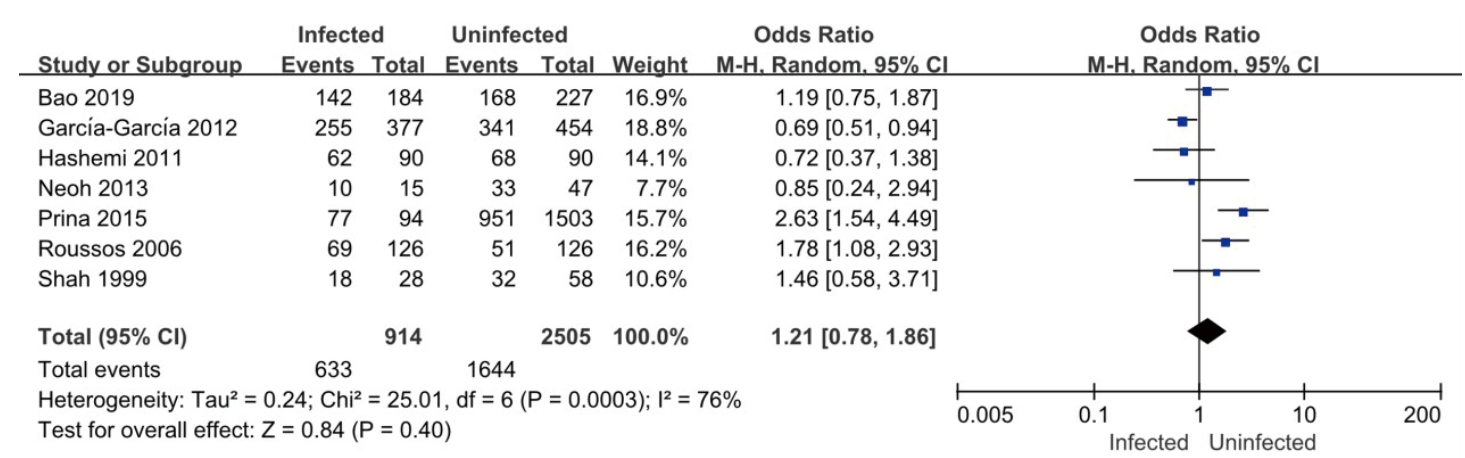

Figure 8 Forest plot of the relationship between pathogen infection and gender.

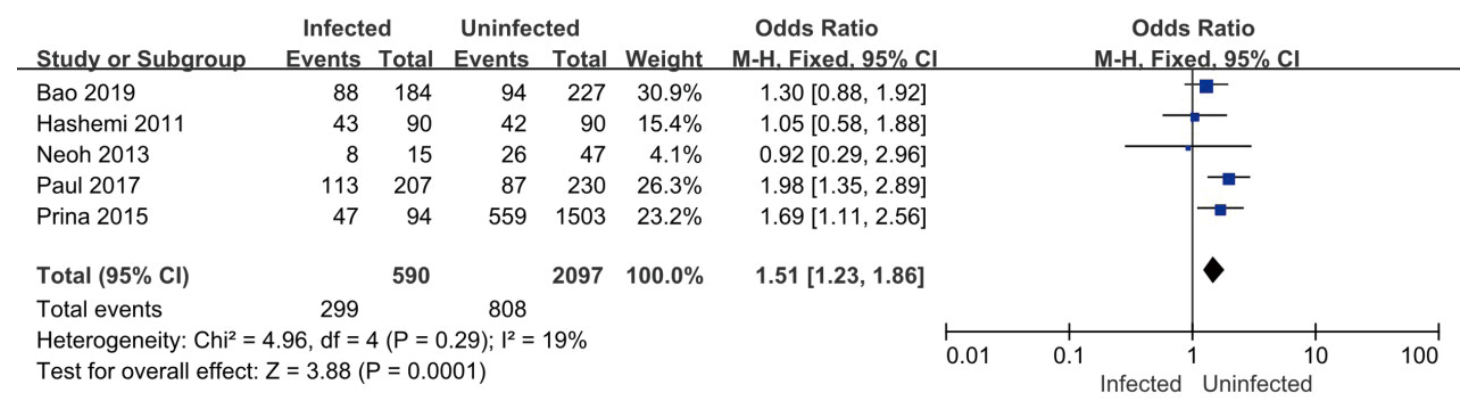

Figure 9 Forest plot of the relationship between pathogen infection and age.

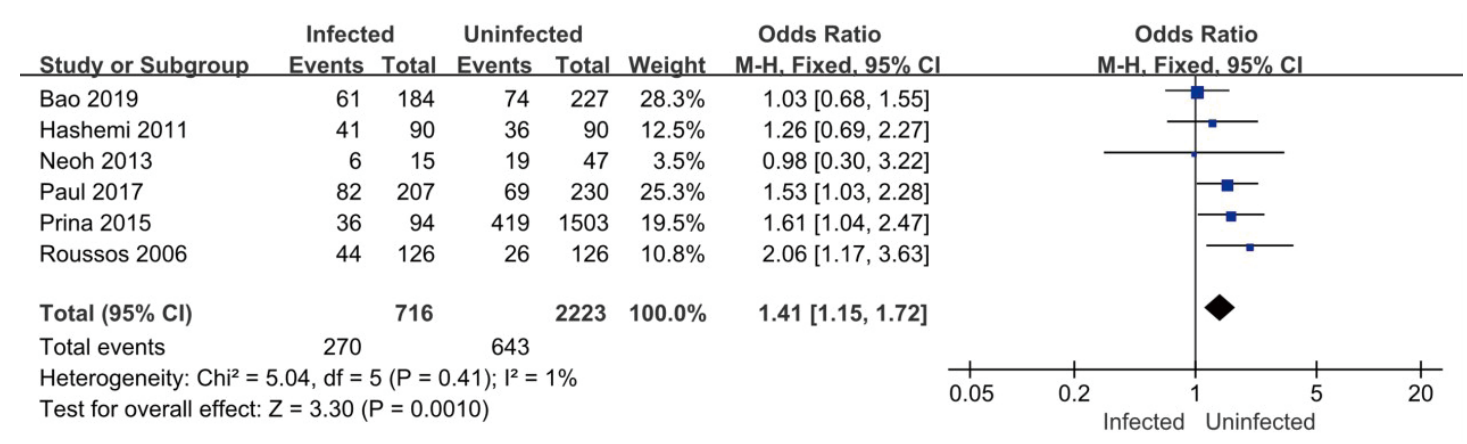

Figure 10 Forest plot of the relationship between pathogen infection and the adoption of antibiotics.

\section{Relationship between pathogenic bacteria infection and the adoption of antibiotics}

Six of the 11 articles included in this study reported on the use of antibiotics in the infected and uninfected groups. A total of 2,939 subjects were enrolled, including 716 patients in the infected group (of whom 270 used antibiotics for more than 14 days), and 2,223 patients in the noninfected group (of whom 643 used antibiotics for more than 14 days). The results of the heterogeneity test showed that the 6 included studies had good homogeneity $\left(I^{2}=1 \%\right.$; $\mathrm{P}=0.41$ ). Thus, a FEM was used for the analysis. The analysis results are shown in Figure 10. The combined effect of the meta-analysis was $\mathrm{MD}=1.41 ; 95 \% \mathrm{CI}$ : $(1.15$, 1.72); $\mathrm{Z}=3.30(\mathrm{P}=0.001)$. There was a statistically significant difference between the number of antibiotics used in the infected group and the uninfected group, which indicated that antibiotic use over 14 days increased the risk of pulmonary mycosis. 


\begin{tabular}{|c|c|c|c|c|c|c|c|c|c|c|}
\hline Study or Subgroup & $\begin{array}{l}\text { Infecte } \\
\text { Events }\end{array}$ & $\begin{array}{l}\text { d } \\
\text { Total }\end{array}$ & $\begin{array}{l}\text { Uninfe } \\
\text { Events }\end{array}$ & $\begin{array}{l}\text { ted } \\
\text { Total }\end{array}$ & Weight & $\begin{array}{l}\text { Odds Ratio } \\
\text { M-H, Random. } 95 \% \mathrm{Cl}\end{array}$ & & $\begin{array}{r}\text { Odds } \\
\text { M-H. Rand }\end{array}$ & $\begin{array}{l}\text { s Ratio } \\
\text { dom. } 95 \% \mathrm{Cl}\end{array}$ & \\
\hline Bao 2019 & 55 & 184 & 59 & 227 & $23.8 \%$ & $1.21[0.79,1.87]$ & & & - & \\
\hline Hashemi 2011 & 28 & 90 & 14 & 90 & $17.6 \%$ & $2.45[1.19,5.06]$ & & & - & \\
\hline Neoh 2013 & 6 & 15 & 19 & 47 & $10.4 \%$ & $0.98[0.30,3.22]$ & & & & \\
\hline Paul 2017 & 75 & 207 & 64 & 230 & $24.4 \%$ & $1.47[0.98,2.21]$ & & & - & \\
\hline Prina 2015 & 39 & 94 & 254 & 1503 & $23.8 \%$ & $3.49[2.26,5.37]$ & & & - & \\
\hline Total $(95 \% \mathrm{Cl})$ & & 590 & & 2097 & $100.0 \%$ & $1.81[1.13,2.91]$ & & & & \\
\hline Total events & 203 & & 410 & & & & & & & \\
\hline \multicolumn{7}{|c|}{$\begin{array}{l}\text { Heterogeneity: } \text { Tau }^{2}=0.20 ; \mathrm{Chi}^{2}=14.88, \mathrm{df}=4(P=0.005) ; \mathrm{I}^{2}=73 \% \\
\text { Test for overall effect: } Z=2.45(P=0.01)\end{array}$} & 0.001 & $\begin{array}{l}0.1 \\
\text { Infected }\end{array}$ & $1 \quad \begin{array}{c}10 \\
\text { Uninfected }\end{array}$ & 1000 \\
\hline
\end{tabular}

Figure 11 Forest plot of the relationship between pathogen infection and the adoption of glucocorticoids.

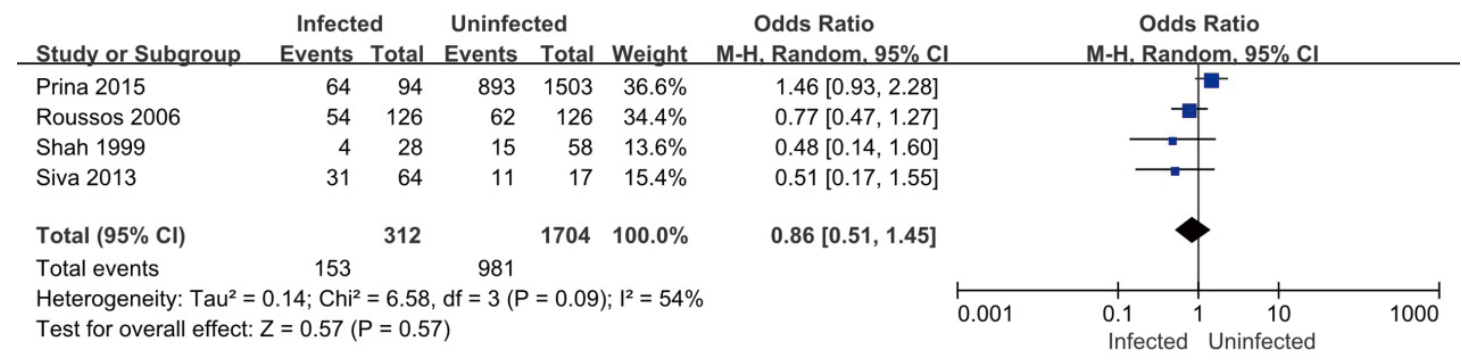

Figure 12 Forest plot of the relationship between pathogen infection and smoking.

\section{Relationship between pathogenic bacteria infection and the adoption of glucocorticoids}

Five of the 11 articles included in this study reported on the use of glucocorticoids in patients in the infected and uninfected groups. A total of 2,687 subjects were enrolled, including 590 in the infected group (of whom 203 were treated with glucocorticoids), and 2,097 in the uninfected group (of whom 410 were treated with glucocorticoids). The results of the heterogeneity test showed that the 5 included studies were quite heterogeneous $\left(\mathrm{I}^{2}=73 \%\right.$; $\mathrm{P}=0.005)$. Thus, a REM was used for the analysis. The analysis results are shown in Figure 11. The combined effect of the meta-analysis was $\mathrm{MD}=1.81 ; 95 \% \mathrm{CI}$ : (1.13, 2.91); $\mathrm{Z}=2.45(\mathrm{P}=0.01)$. There was a significant statistical difference between the number of glucocorticoids used in the infected group and the uninfected group, which indicated that the use of glucocorticoids increased the risk of pulmonary mycosis.

\section{Relationship between pathogenic bacteria infection and smoking}

Four of the 11 articles included in this study reported on the smoking status of patients in the infected and non- infected groups. A total of 2,016 subjects were included in the study, including 312 patients in the infected group (of whom 153 had a history of smoking), and 1,704 patients in the uninfected group (of whom 981 had a history of smoking). The results of the heterogeneity test showed that the 4 included studies were quite heterogeneous $\left(\mathrm{I}^{2}=54 \%\right.$; $\mathrm{P}=0.09)$. Thus, a REM was used for the analysis. The analysis results are shown in Figure 12. The combined effect size of the meta-analysis was $\mathrm{MD}=0.86 ; 95 \% \mathrm{CI}$ : $(0.51$, 1.45); $\mathrm{Z}=0.57(\mathrm{P}=0.57)$. The number of smokers in the infected group was not significantly different from that in the uninfected group, which indicated that smoking did not increase the risk of pulmonary mycosis.

\section{Publication bias analysis of the high-risk factors of pulmonary mycosis}

Review Manager 5.3 was employed to draw a funnel plot of high-risk factors for pulmonary mycosis and perform a publication bias analysis. The results are shown in Figure 13. In the funnel plots for mortality, age, antibiotic use, glucocorticoid use, and smoking history, some scattered points representing the corresponding articles were basically distributed within a credible interval, which suggested that the possibility of publication bias appeared to be low. In 
A

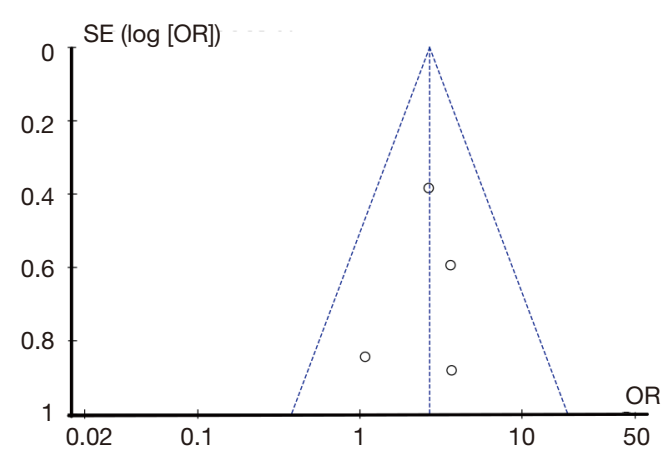

C

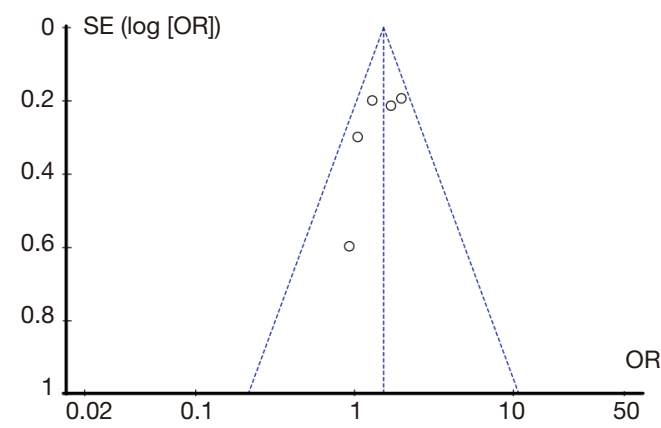

$\mathrm{E}$

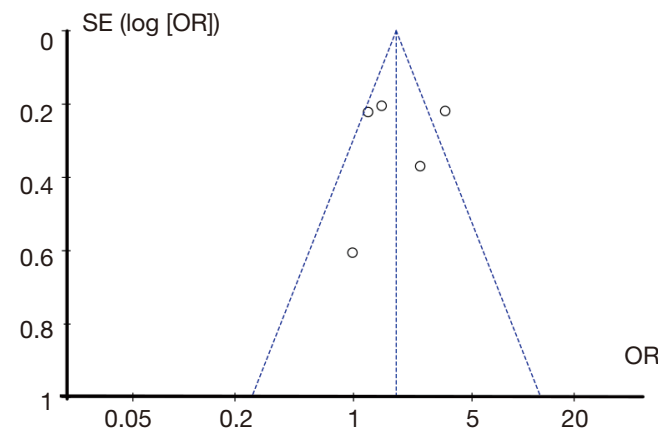

B

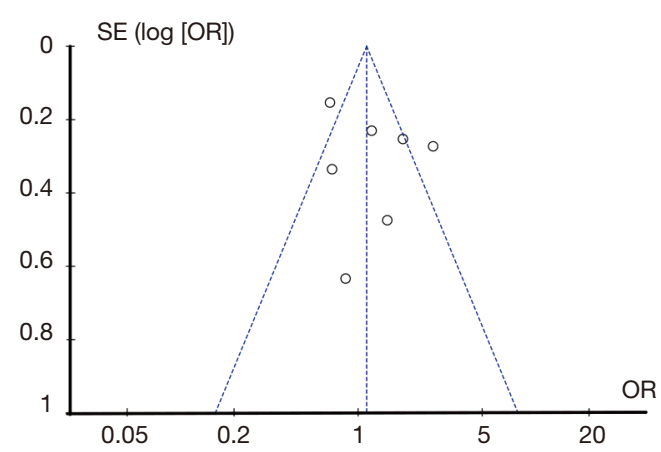

D

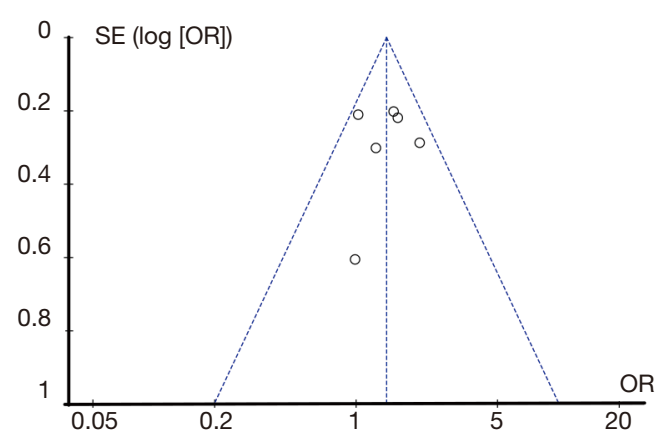

$\mathrm{F}$

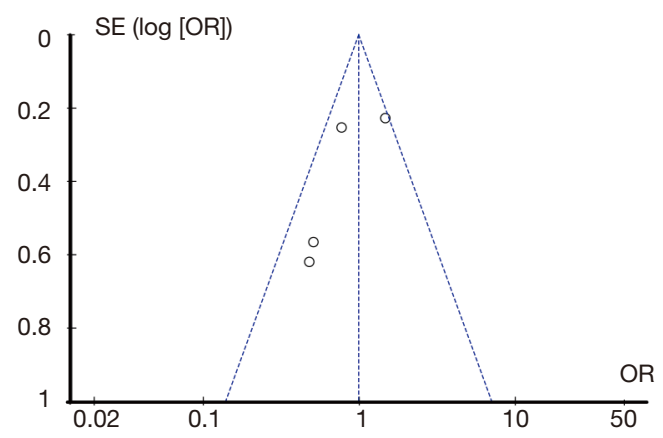

Figure 13 Publication bias analysis of the high-risk factors of pulmonary mycosis. (A) Mortality; (B) gender; (C) age; (D) antibiotic use; (E) glucocorticoid use; (F) smoking history.

the funnel plot of patient gender, some scattered points fell outside the credible interval, which suggested that there was a certain publication bias in the literature.

\section{Discussion}

In recent years, with the extensive development of organ transplantation and the extensive use of broad-spectrum antimicrobial drugs and immunosuppressants, the incidence of pulmonary fungal infection has gradually increased.
Currently, empirical treatment strategies are usually used in clinical treatment of pulmonary mycosis $(24,25)$. Pulmonary mycosis is dominated by invasive infection, so it is necessary to strengthen the dynamic monitoring of the high incidence of pathogenic bacteria in pulmonary mycosis in clinical treatment. In addition, screening and identification of highrisk factors should be strengthened to realize early detection and treatment of patients with pulmonary mycodisease and improve the prognosis of patients (26).

This meta-analysis included a total of 11 articles, 
including 6,415 cases of study subjects. The types of infections, infection sites, and high-risk factors of the pathogenic bacteria of pulmonary fungal disease were explored. The results showed that the main types of lung fungal infections were Pseudomonas aeruginosa, Haemophilus influenzae, Streptococcus pneumoniae, Helicobacter pylori, and Candida albicans. The infection sites were mainly infections of the lungs, intestines, urinary tract, and digestive tract. The reason may be that the clinical invasive operation destroys the mucosal barrier of the respiratory tract, leading to fungal infection of the lungs. After the risk factors of pulmonary mycosis were analyzed, it was found that the mortality of patients in the infected group was higher than that in the non-infected group, and the age of patients was related to the incidence of pulmonary mycosis. Patients older than 60 years of age had an increased incidence of pulmonary mycosis. The use of antibiotics and glucocorticoids also increased the risk of pulmonary mycosis. However, gender and smoking history of patients had no significant effect on the incidence of pulmonary mycosis, which was similar to the opinion of Haydour et al. (27). The reason may be that the onset of pulmonary mycosis may be related to the patient's physical condition. The elderly had an increased incidence of pulmonary mycosis due to low immune function and other basic diseases. In addition, long-term use of antibiotics can inhibit the normal flora in the body, resulting in imbalance of flora, leading to an increase in the incidence of fungal infections. The continued use of glucodermatin may inhibit the chemotaxis of white blood cells and weaken the function of phagocytes and lymphocytes. While reducing inflammation, it also reduces the body's immune response, leading to fungal infection of the lungs.

\section{Conclusions}

The types of infections, infection sites, and high-risk factors of the pathogenic bacteria of pulmonary fungal disease were explored. It was revealed that the main types of lung fungal infections were Pseudomonas aeruginosa, Haemophilus influenzae, Streptococcus pneumoniae, Helicobacter pylori, and Candida albicans. The infection was related to the age of the patients and the use of antibiotics and glucocorticoids. Therefore, appropriate measures should be taken to prevent fungal infection in the clinical treatment of pulmonary mycosis. Reasonable use of drugs and strengthening the monitoring of pathogenic bacteria can effectively control nosocomial fungal infections and effectively reduce the mortality of invasive abdominal fungal infections. However, this study also has some deficiencies, which are manifested as a small number of included studies and no analysis of factors such as mechanical ventilation and invasive procedures, leading to certain limitations of this study. Therefore, more high-quality, multi-center, and large sample controlled clinical trials are still needed in future studies. The distribution of pathogenic bacteria and high risk factors of pulmonary mycosis will be further analyzed to provide a more sufficient basis for the treatment and prognosis of patients with pulmonary mycosis.

\section{Acknowledgments}

Funding: None.

\section{Footnote}

Reporting Checklist: The authors have completed the PRISMA reporting checklist. Available at https://dx.doi. org/10.21037/apm-21-1388

Conflicts of Interest: All authors have completed the ICMJE uniform disclosure form (available at https://dx.doi. org/10.21037/apm-21-1388). The authors have no conflicts of interest to declare.

Ethical Statement: The authors are accountable for all aspects of the work in ensuring that questions related to the accuracy or integrity of any part of the work are appropriately investigated and resolved.

Open Access Statement: This is an Open Access article distributed in accordance with the Creative Commons Attribution-NonCommercial-NoDerivs 4.0 International License (CC BY-NC-ND 4.0), which permits the noncommercial replication and distribution of the article with the strict proviso that no changes or edits are made and the original work is properly cited (including links to both the formal publication through the relevant DOI and the license). See: https://creativecommons.org/licenses/by-nc-nd/4.0/.

\section{References}

1. Villalobos APC, Husain S. Infection prophylaxis and management of fungal infections in lung transplant. Ann Transl Med 2020;8:414.

2. Dahiya S, Chhillar AK, Sharma N, et al. Candida auris and 
Nosocomial Infection. Curr Drug Targets 2020;21:365-73.

3. Ma H, Wang J, Ma X, et al. Video-assisted thoracoscopic surgery for invasive pulmonary fungal infection in haematology patients. J Thorac Dis 2019;11:2839-45.

4. Setianingrum F, Rautemaa-Richardson R, Denning DW. Pulmonary cryptococcosis: A review of pathobiology and clinical aspects. Med Mycol 2019;57:133-50.

5. Capoor MR, Agarwal P, Goel M, et al. Invasive pulmonary mycosis due to Chaetomium globosum with false-positive galactomannan test: a case report and literature review. Mycoses 2016;59:186-93.

6. Shen Q, Yao YK, Yang Q, et al. Schizophyllum communeinduced Pulmonary Mycosis. Chin Med J (Engl) 2016;129:2141-2.

7. Salzer HJF, Burchard G, Cornely OA, et al. Diagnosis and Management of Systemic Endemic Mycoses Causing Pulmonary Disease. Respiration 2018;96:283-301.

8. Sartori A, Souza A, Zanon M, et al. Performance of magnetic resonance imaging in pulmonary fungal disease compared to high-resolution computed tomography. Mycoses 2017;60:266-72.

9. Ocakcioglu I, Ermerak NO, Yildizeli B. Uniportal Video-assisted Thoracoscopic Surgery for Pulmonary Aspergilloma: A Report of 5 Cases. Surg Laparosc Endosc Percutan Tech 2019;29:e37-40.

10. Yan X, Zong F, Kong H, et al. Pulmonary Fungal Diseases in Immunocompetent Hosts: A Single-Center Retrospective Analysis of 35 Subjects. Mycopathologia 2016;181:513-21.

11. Wang J, Zu Q, Wang W. Analysis of factors of pulmonary fungal infection in mice in respiratory medicine department based on logistic regression analysis model and Progranulin. Saudi J Biol Sci 2020;27:629-35.

12. Jacobs SE, Wengenack NL, Walsh TJ. Non-Aspergillus Hyaline Molds: Emerging Causes of Sino-Pulmonary Fungal Infections and Other Invasive Mycoses. Semin Respir Crit Care Med 2020;41:115-30.

13. Shah PL, Mawdsley S, Nash K, et al. Determinants of chronic infection with Staphylococcus aureus in patients with bronchiectasis. Eur Respir J 1999;14:1340-4.

14. Roussos A, Philippou N, Mantzaris GJ, et al. Respiratory diseases and Helicobacter pylori infection: is there a link? Respiration 2006;73:708-14.

15. Hashemi SH, Nadi E, Hajilooi M, et al. Relationship between Helicobacter pylori infection and chronic obstructive pulmonary disease. Acta Med Iran 2011;49:721-4.

16. García-García ML, Calvo C, Pozo F, et al. Spectrum of respiratory viruses in children with community-acquired pneumonia. Pediatr Infect Dis J 2012;31:808-13.

17. Neoh CF, Snell GI, Levvey B, et al. Preemptive treatment with voriconazole in lung transplant recipients. Transpl Infect Dis 2013;15:344-53.

18. Siva R, Birring SS, Berry M, et al. Peptic ulceration, Helicobacter pylori seropositivity and chronic obstructive pulmonary disease. Respirology 2013;18:728-31.

19. Prina E, Ranzani OT, Polverino E, et al. Risk factors associated with potentially antibiotic-resistant pathogens in communityacquired pneumonia. Ann Am Thorac Soc 2015;12:153-60.

20. Hasegawa K, Pate BM, Mansbach JM, et al. Risk factors for requiring intensive care among children admitted to ward with bronchiolitis. Acad Pediatr 2015;15:77-81.

21. Paul SP, Mukherjee A, McAllister T, et al. Respiratorysyncytial-virus- and rhinovirus-related bronchiolitis in children aged $<2$ years in an English district general hospital. J Hosp Infect 2017;96:360-5.

22. Bao Q, Zhou H, Chen X, et al. Characteristics and Influencing Factors of Pathogenic Bacteria in Lung Cancer Chemotherapy Combined with Nosocomial Pulmonary Infection. Zhongguo Fei Ai Za Zhi 2019;22:772-8.

23. Li L, Hsu SH, Gu X, et al. Aetiology and prognostic risk factors of mortality in patients with pneumonia receiving glucocorticoids alone or glucocorticoids and other immunosuppressants: a retrospective cohort study. BMJ Open 2020;10:e037419.

24. Roden AC, Schuetz AN. Histopathology of fungal diseases of the lung. Semin Diagn Pathol 2017;34:530-49.

25. Ho DK, Nichols BLB, Edgar KJ, et al. Challenges and strategies in drug delivery systems for treatment of pulmonary infections. Eur J Pharm Biopharm 2019;144:110-24.

26. Schwarz C, Brandt C, Whitaker P, et al. Invasive Pulmonary Fungal Infections in Cystic Fibrosis. Mycopathologia 2018;183:33-43.

27. Haydour Q, Hage CA, Carmona EM, et al. Diagnosis of Fungal Infections. A Systematic Review and Meta-Analysis Supporting American Thoracic Society Practice Guideline. Ann Am Thorac Soc 2019;16:1179-88.

(English Language Editor: L. Huleatt)

Cite this article as: Lin J, Feng B, Tang H, Xu H, Tang Y. A systematic review and meta-analysis: pulmonary mycosis pathogen distribution. Ann Palliat Med 2021;10(7):7919-7932. doi: 10.21037/apm-21-1388 